\title{
Effect of a network system for providing proper inhalation technique by community pharmacists on clinical outcomes in COPD patients
}

This article was published in the following Dove Press journal:

International Journal of COPD

8 May 2013

Number of times this article has been viewed

\author{
Masaya Takemura' \\ Katsumi Mitsui ${ }^{2}$ \\ Masako Ido \\ Masataka Matsumoto' \\ Misuzu Koyama ${ }^{3}$ \\ Daiki Inoue' \\ Kazufumi Takamatsu' \\ Ryo Itotani' \\ Manabu Ishitoko' \\ Shinko Suzuki' \\ Kensaku Aihara' \\ Minoru Sakuramoto' \\ Hitoshi Kagioka' \\ Motonari Fukui' \\ 'Respiratory Disease Center, \\ Kitano-Hospital, the Tazuke Kofukai \\ Medical Research Institute, Osaka, \\ Japan; ${ }^{2}$ Division of Pharmacy, \\ Kitano-Hospital, The Tazuke Kofukai \\ Medical Research Institute, Osaka, \\ Japan; ${ }^{3}$ Kita-ku Pharmaceutical \\ Association, Osaka, Japan
}

Correspondence: Masaya Takemura Respiratory Disease Center, Kitano Hospital, The Tazuke Kofukai Medical Research Institute, 2-4-20 Ohgimachi, Kita-ku, Osaka 530-8480, Japan

$\mathrm{Tel}+8|663| 2|22|$

Fax $+8|6636| 0588$

Email m-takemura@kitano-hp.or.jp
Introduction: Nonadherence to inhalation therapy is very common in patients with chronic obstructive pulmonary disease (COPD). Few data are available to support the role of community pharmacists in optimizing inhalation therapy in COPD patients. Since 2007, the Kitano Hospital and the Kita-ku Pharmaceutical Association have provided a network system for delivering correct inhalation techniques through certified community pharmacists. The effects of this network system on clinical outcomes in COPD patients were examined.

Methods: A total of 88 consecutive outpatients with COPD at baseline and 82 of those 4 years later were recruited from the respiratory clinic of Kitano Hospital Medical Research Institute. Measurements included the frequency of COPD exacerbations, patients' adherence to inhalation therapy using a five-point Likert scale questionnaire, and patients' health status both prior to this system and 4 years later.

Results: Usable information was obtained from 55 patients with COPD at baseline, and from 51 patients 4 years later. Compared with baseline values, a significant decrease was observed in the frequency of COPD exacerbations $(1.5 \pm 1.6$ versus $0.8 \pm 1.4$ times/year, $P=0.017)$. Adherence to the inhalation regimen increased significantly $(4.1 \pm 0.7$ versus $4.4 \pm 0.8$, $P=0.024)$, but health status was unchanged. At 4 years, of 51 COPD patients, 39 (76\%) patients who visited the certified pharmacies showed significantly higher medication adherence than those who did not $(4.6 \pm 0.6$ versus $3.9 \pm 1.0, P=0.022)$.

Conclusion: The network system may improve COPD control and adherence to inhalation regimens.

Keywords: COPD, adherence, community pharmacist, exacerbation, quality of life

\section{Introduction}

Chronic obstructive pulmonary disease (COPD) represents a major public health problem in terms of prevalence, mortality, impaired quality of life, and economic costs. In addition to smoking cessation, inhalation therapy constitutes the mainstay of COPD management. ${ }^{1}$ Recent large-scale, long-term, and landmark studies have reported that a combination of a long-acting $\beta_{2}$ agonist (salmeterol) and inhaled corticosteroid (fluticasone) modify the long-term decline in lung function, and an inhaled long-acting anticholinergic agent (tiotropium) appears to reduce mortality in COPD patients. ${ }^{2,3}$ However, in practice, many COPD patients are nonadherent to inhalation therapy. Some studies have demonstrated that approximately $60 \%$ of COPD patients are nonadherent to their inhalation regimen. ${ }^{4-6}$ Furthermore, many patients make a number of critical errors in using an inhaler device. ${ }^{7}$ Nonadherence to inhaled medication in COPD may be related to poor prognosis. A recent study revealed that the mortality rate was more than twice among COPD patients who 
were nonadherent to their inhalation regimen compared with those that were adherent, when adherence is defined as $>80 \%$ use of prescribed medication. $^{8}$

Factors that improve adherence to inhalation therapy in COPD have not been fully addressed. Our previous crosssectional study showed that instructions on inhalation technique repeatedly provided for COPD patients contribute to adherence to therapeutic regimens and a significant positive relationship between adherence to the inhalation regimen and health status was demonstrated. ${ }^{9}$

Since 2007, we have developed "A Network system for Providing Proper Inhalation Technique" (NEPPIT) aimed at providing an educational program for community pharmacists to offer repeated instruction in correct and consistent inhalation technique to patients. We have previously reported the effects of NEPPIT on community pharmacists and asthma patients. ${ }^{10}$ Briefly, during the 4-year study period, the community pharmacists who attended our educational program were in $70 \%$ of the 81 community pharmacies in the northern area of Osaka. As compared with baseline values, at 4 years after the introduction of NEPPIT, the number of pharmacies stocking the materials for instruction increased by $30 \%$, the frequency of pharmacists' instruction on inhalation therapy more than tripled, and the population of pharmacists who gave verbal instruction and physical demonstrations of inhalation technique increased by $30 \%$, resulting in a $30 \%$ and $60 \%$ reduction in the frequency of asthma exacerbations and emergency room visits, respectively, and improved adherence to inhalation therapy in asthma patients. ${ }^{10}$ This study aimed to evaluate the long-term effects of our network system on clinical outcomes in COPD patients.

\section{Methods}

\section{Study design}

A prospective, pre-post, nonequivalent group study was carried out between November 2006 and December 2010. In April 2007, a network system of community pharmacists instructing patients on the correct inhalation technique was implemented. The information concerning patients' inhaler use was shared between prescribers and community pharmacists. The clinical effects of this network system on the frequency of COPD exacerbations, patients' adherence to inhalation therapy, and health-related quality of life (QOL) were examined at baseline and 4 years later.

\section{Study subjects}

Eighty-eight consecutive outpatients with COPD at baseline and 82 of those at 4 years who were referred to the respiratory clinic of the Kitano Hospital Medical Research Institute were recruited. Subjects were eligible for participation in the study if they met the following criteria: (1) current or former smoker ( $>10$ pack-years); (2) regular visits to the respiratory outpatient clinic every 1 to 3 months; (3) respiratory physician diagnosed COPD; (4) physician prescribed inhaled medicines (anticholinergic, $\beta_{2}$ agonist, inhaled corticosteroid [ICS], and/ or combined inhaler device of ICS and $\beta_{2}$ agonist for at least 12 months); and (5) no change in COPD inhaler medication for 3 months. Patients' data were obtained from their medical records. The diagnosis and staging of COPD were confirmed by the lung function criteria of the Global Initiative for Chronic Obstructive Lung Disease (GOLD) guideline. ${ }^{1}$ The patients who still smoked were referred to a smoking cessation outpatient service run within the hospital.

Informed consent was obtained from all participants, and the research protocol was approved by the ethics committee of the Kitano Hospital, at the Tazuke Kofukai Medical Research Institute.

\section{System of NEPPIT}

NEPPIT has been in place since April 2007 through cooperation between the Kitano Hospital and the Kita-ku Pharmaceutical Association, which consists of 81 community pharmacies in the northern area of Osaka, Japan. The main component of this system is an educational program for community pharmacists aimed at providing correct and consistent inhalation technique to patients. Through the program, all pharmacists received general information regarding the pathophysiology of asthma and COPD, inhaled medication such as anticholinergic, ICS, and $\beta_{2}$ agonists, adherence to inhalation therapy, and inhalation technique. This educational program emphasized correct inhaler technique through lectures, role-playing, and skills training for each inhaler device. We provided participants with materials for instruction, such as training inhalers with placebo and checklists for the inhalation technique of each device. After training, they were able to demonstrate and give instruction about the correct inhaler technique for all of the devices. Subsequently, they were certified and registered as inhalation technique instructors and were encouraged to instruct patients on proper inhaler technique at regular intervals (at least every 6 months). A pharmacy with certified pharmacist(s) was defined as a certified pharmacy. To keep up with new trends in inhalation therapy, the validity of this certificate was limited to 2 years, and certified pharmacists were encouraged to attend our further educational program within 2 years. 
COPD patients in the study were given a pocket-sized booklet with detailed instructions on correct inhaler use and answers to common questions and concerns that patients have about using inhalers. Prescribers asked patients to carry this booklet and show it to pharmacists for the purpose of checking their inhaler technique. Certified pharmacists were to report the status of patients' inhalation technique to prescribers using a checklist and entering comments in the booklet.

\section{Outcome measurements}

\section{Questionnaire regarding inhalation therapy}

The data collection was done by the staff of the outpatient clinic of the Kitano Hospital. Potential study participants were approached in the waiting room by the researcher and were invited to answer a questionnaire prior to their appointment. The medical clerks helped collect the data of questionnaire. The Self-Reported Medication Adherence Questionnaire was administered as described previously. ${ }^{9-13}$ This adherence questionnaire is an adaptation of a scale originally developed by Morisky et al. ${ }^{14,15}$ This scale consists of four questions pertaining to the use of inhaled controller medications. There were five response options for each question. For example, for the question, "During the last 3 months, have you: (1) Been careless about using your inhaler?; (2) Ever forgotten to use your inhaler?; (3) Ever stopped using your inhaler because you felt better?; (4) Used your inhaler less than your doctor prescribed because you felt better?" responses ranged from 1 to 5, with a score of 1 indicating "Most of the time," a score of 3 indicating, "Some of the time," and a score of 5 indicating, "None of the time."

The self-reported adherence score was calculated from the mean of the responses to the four questions. Higher scores reflected better adherence to the inhalation regimen. Previous research has demonstrated that self-reported adherence assessed with this questionnaire correlates well with adherence determined by pharmacy claims data. ${ }^{11}$ Improper responses to these five questions were excluded from the analysis.

\section{Health-related quality of life questionnaire}

The St George Respiratory Questionnaire (SGRQ) was used to measure the health-related QOL of COPD patients. ${ }^{16,17}$ The responses to its 50 items can be aggregated into a total score and three subscores for symptoms (measuring distress caused by respiratory symptoms), activities (measuring the effect of disturbances to mobility and physical activity), and impacts (quantifying the psychosocial impact of the disease). Scores range from 0 to 100 , with higher scores reflecting worse health status. ${ }^{16,17}$ The Japanese version of the SGRQ has been validated. ${ }^{18}$ The SGRQ and the adherence questionnaire were given to the patients on the same day.

\section{COPD exacerbations}

Information on the frequency of COPD exacerbations was obtained from the patients' medical records in the 12 months preceding questionnaire administration. Exacerbation of COPD was defined as symptomatic deterioration (dyspnea, cough, sputum purulence/volume, or wheeze) that required treatment with oral corticosteroids and/or antibiotics or hospitalization.

\section{Analysis}

Values are expressed as means ( \pm standard deviation). The data were analyzed using Stat View 5.0 (SAS Institute, Cary, NC, USA). Comparisons between groups were made with the Mann-Whitney $U$ test, Fisher's exact probability test, or the chi-square test for univariate analysis. A value of $P<0.05$ indicated significance.

\section{Results \\ Comparison of COPD patients' characteristics at baseline and at 4 years}

Of the 88 patients at baseline and the 82 patients at 4 years, $55(63 \%)$ and $51(62 \%)$ responded with usable information, respectively. There were no differences in age and sex between respondents and nonrespondents in each survey period (data not shown). No differences were found in age, sex, smoking status, frequency of patients' clinic visits, duration of disease, period and frequency of inhaler use, type of inhaler, presence of comorbidities, taking of antipsychotic drugs, and prevalence of COPD stage between baseline values and at 4 years. Pulmonary function expressed as forced expiratory volume $\left(\mathrm{FEV}_{1}\right)$ percent predicted value and $\mathrm{FEV}_{1} /$ forced vital capacity showed a tendency to be lower at 4 years compared with baseline values. At 4 years, 39 (76.4\%) of 51 patients visited the NEPPIT-certified community pharmacies at regular intervals, and the remaining 12 patients visited other pharmacies (Table 1).

\section{Comparison of outcome measures at baseline and 4 years}

Compared with baseline, 4 years after the start of the network system, there was a significant decrease in the frequency of COPD exacerbations $(1.5 \pm 1.6 /$ year to $0.8 \pm 1.4 /$ year, $P=0.017$ ) and a significant increase in the proportion of COPD patients adherent to inhalation 
Table I Comparison of patients' characteristics at baseline and 4 years later

\begin{tabular}{llll}
\hline & Baseline & 4 years & P-value \\
\hline Patients (number) & 55 & $5 \mathrm{I}$ & \\
Age (years) & $69(8)$ & $69(8)$ & 0.90 \\
Sex (female) & 15 & 7 & 0.09 \\
Current smoking (yes) & 8 & 5 & 0.46 \\
Frequency of clinic visits & $8(4-18)$ & $7(4-18)$ & 0.86 \\
(per year) & & & \\
Duration of disease (years) & $8.1(10.6)$ & $7.4(12.1)$ & 0.20 \\
Period of inhaler use (years) & $5.9(6.7)$ & $4.7(6.0)$ & 0.26 \\
Freq of inhaler use (per day) & $2.4(1.0)$ & $1.9(0.8)$ & 0.18 \\
Type of Inhaler & $18: 18: 19$ & $12: 27: 12$ & 0.11 \\
(MDI:DPI:MDI + DPI) & & & \\
Presence of comorbidities & 37 & 36 & 0.70 \\
Taking of antipsychotic drugs & 13 & 12 & 0.99 \\
Stage of COPD (I, 2, 3, 4) & $13,30,9,3$ & $10,22,15,4$ & 0.37 \\
FEV $\%$ predicted value (\%) & $68.1(16.0)$ & $61.0(18.4)$ & 0.052 \\
FEV,/FVC (\%) & $56.3(13.1)$ & $50.6(14.4)$ & 0.058 \\
Number of patients regularly & - & 39 & \\
visiting a certified pharmacy & & &
\end{tabular}

Abbreviations: MDI, metered-dose inhaler; DPI, dry powder inhaler; FEV, forced expiratory volume; FVC, forced vital capacity; COPD, chronic obstructive pulmonary disease.

therapy ( $4.1 \pm 0.7$ to $4.4 \pm 0.8, P=0.024)$, but there were no significant differences in SGRQ scores (Table 2).

\section{Comparison of patient characteristics and outcomes between COPD patients who visited a certified pharmacy and those who did not (at 4 years)}

There was a significantly higher medication adherence for patients who visited a certified pharmacy compared with those who did not $(4.6 \pm 0.6$ versus $3.9 \pm 1.0, P=0.022)$ (Table 3). As for other items, there were no significant differences in patient characteristics and outcomes, including frequency of COPD exacerbations and SGRQ scores, between those who visited a certified pharmacy and those who visited a usual care pharmacy.

Table 2 Comparison of outcome measures in COPD patients at baseline and 4 years later

\begin{tabular}{llll}
\hline & Baseline & 4 years & P-value \\
\hline $\begin{array}{l}\text { Patients (number) } \\
\begin{array}{l}\text { Frequency of exacerbations } \\
\text { (per year) }\end{array}\end{array}$ & 55 & 51 & \\
$\begin{array}{l}\text { Overall mean adherence score } \\
\text { SGRQ scores }\end{array}$ & $4.1(0.7)$ & $4.4(0.8)$ & 0.024 \\
$\quad$ Symptoms (0-100) & $47.3(25.9)$ & $50.2(21.2)$ & 0.60 \\
$\quad$ Activities (0-100) & $47.4(21.9)$ & $48.2(26.2)$ & 0.79 \\
$\quad$ Impacts (0-100) & $31.3(21.9)$ & $28.8(19.3)$ & 0.78 \\
$\quad$ Total (0-100) & $40.4(20.1)$ & $40.8(20.8)$ & 0.99 \\
\hline
\end{tabular}

Abbreviations: COPD, chronic obstructive pulmonary disease; SGRQ, St George Respiratory Questionnaire.
Table 3 Comparison of COPD patients' characteristics and outcomes at 4 years between patients visiting the certified pharmacy and those visiting the usual care pharmacy

\begin{tabular}{|c|c|c|c|}
\hline \multirow[t]{2}{*}{ Community pharmacy } & \multicolumn{2}{|l|}{4 years } & \multirow[t]{2}{*}{$P$-value } \\
\hline & Certified & Usual & \\
\hline Patients (number) & 39 & 12 & \\
\hline Age (years) & $68.6(8.2)$ & $71.4(8.0)$ & 0.24 \\
\hline Sex (female) & 7 & 0 & 0.11 \\
\hline Current smoking (yes) & 4 & 1 & 0.84 \\
\hline Frequency of clinic visits (years) & $8.0(3.3)$ & $7.4(2.6)$ & 0.73 \\
\hline Duration of disease (years) & $8.3(12.3)$ & $4.3(3.1)$ & 0.76 \\
\hline Period of inhaler use (years) & $5.0(6.5)$ & $3.3(2.7)$ & 0.99 \\
\hline Freq of inhaler use (per day) & $2.2(0.5)$ & $2.2(0.7)$ & 0.93 \\
\hline \multicolumn{4}{|l|}{ (MDI:DPI:MDI + DPI) } \\
\hline Presence of comorbidities & 10 & 4 & 0.60 \\
\hline Taking antipsychotic drugs & 9 & 3 & 0.89 \\
\hline Stage of COPD $(I, 2,3,4)$ & $8,14,13,4$ & $2,8,2,0$ & 0.24 \\
\hline FEV,\% predicted value (\%) & $58.7(19.0)$ & $67.3(15.8)$ & 0.16 \\
\hline $\mathrm{FEV}_{1} / \mathrm{FVC}(\%)$ & $48.5(14.6)$ & $56.8(12.4)$ & 0.13 \\
\hline Freq of exacerbations (/year) & $0.8(1.4)$ & $0.4(1.2)$ & 0.34 \\
\hline Overall mean adherence score & $4.6(0.6)$ & $3.9(1.0)$ & 0.022 \\
\hline \multicolumn{4}{|l|}{ SGRQ scores } \\
\hline Symptoms $(0-100)$ & $51.6(22.6)$ & $45.1(15.1)$ & 0.43 \\
\hline Activities $(0-100)$ & $51.4(26.7)$ & $37.5(24.6)$ & 0.16 \\
\hline Impacts $(0-100)$ & $29.6(17.5)$ & $25.7(26.2)$ & 0.37 \\
\hline Total $(0-100)$ & $42.5(19.7)$ & $34.3(24.8)$ & 0.25 \\
\hline
\end{tabular}

Abbreviations: COPD, chronic obstructive pulmonary disease; MDI, metered dose inhaler; DPI, dry powder inhaler; FEV, forced expiratory volume; FVC, forced vital capacity; SGRQ, St George Respiratory Questionnaire.

\section{Discussion}

A prospective study measuring adherence to inhaled therapy, frequency of COPD exacerbations, and health status at baseline and 4 years later was carried out. Compared with baseline, a significant reduction in the frequency of COPD exacerbations and an improved adherence to inhalation therapy were demonstrated 4 years after the start of the NEPPIT system. At 4 years, 39 (76\%) of 51 COPD patients regularly visited certified pharmacies in which pharmacists trained as inhalation instructors provided patients with proper inhalation technique at regular intervals. Patients who visited certified pharmacies showed a significantly better adherence to inhalation therapy than those who did not.

Many publications in the past decade have reported that well-trained pharmacists could enhance therapeutic outcomes in patients with asthma. ${ }^{19-25}$ The need to consider pharmacist interventions for COPD patients has also been highlighted. Some well-designed, randomized, controlled studies have reported the effects of pharmacist care for COPD patients. For example, a study involving 173 COPD patients evaluated an educational program focused on self-management administered by a clinical pharmacist. During the 12-month 
study period, the patients allocated to the intervention group demonstrated improvements in COPD knowledge, medication adherence, and humanistic outcomes assessed by the SGRQ, and reductions in both hospital admissions and emergency room visits when compared with control patients. ${ }^{26}$ Another study including 133 COPD patients showed that a single educational program provided by community pharmacists resulted in significant improvements in COPD knowledge, medication adherence, medication beliefs, and reduction in hospital admission rates in intervention patients when compared with a control group between baseline and 6 months later. ${ }^{27}$ Thus, community pharmacists are well positioned to perform medication- and wellness-related interventions that can improve patient outcomes. The short-term effectiveness of an educational program for community pharmacists in improving clinical outcomes of COPD patients has been established, but long-term effects remain a challenge. The strength of the present study was the long-term design in order to confirm the clinical outcomes of the network system in COPD patients.

The NEPPIT system contributed to significant improvement in medication adherence and reduction in COPD exacerbation rates 4 years after it was started. When considering the reason why this system affects clinical outcomes in COPD patients, one possible explanation is improving the skill of pharmacists' instruction on inhalation technique. As we previously reported, NEPPIT improved the quality and quantity of pharmacists' instruction, such as more pharmacies stocking the materials for instruction and more pharmacists giving verbal instructions and physical demonstrations of inhalation technique, resulting in improved clinical outcomes in asthma patients. ${ }^{10}$ Similarly, improvements in community pharmacists' instruction seemed to be reflected in better clinical outcomes in COPD patients. In the present study, at 4 years, $76.5 \%$ of COPD patients regularly visited the certified community pharmacy, and the remaining patients visited uncertified pharmacies. Indeed, COPD patients with instruction from a certified pharmacist on inhalation technique showed significantly better adherence to inhalation therapy than patients visiting a usual care pharmacist. The other possible reason for the positive results is repeated instruction regularly provided by community pharmacists. Our previous preliminary cross-sectional study demonstrated that COPD patients who received repeated instruction on inhalation technique showed better medication adherence and better health status than those who did not receive instruction. ${ }^{9}$ Based on these data, NEPPIT has emphasized the necessity of repeated instruction on proper inhaler technique at least every 6 months. The present study confirmed its clinical impact and effect 4 years after the start of the system.

As several studies reported, the beneficial effect of pharmaceutical intervention on health-related QOL remains controversial. ${ }^{27-30}$ The present study also failed to demonstrate improvement of health status on the SGRQ. It is not easy to interpret this result, but a more intensive program, such as promotion of physical activity and ventilatory support, might be needed to improve QOL.

The present study had some limitations. First, the sample size of the study was small. Second, patients were not randomized to usual or interventional care groups. In that setting, however, pharmacists would have to follow-up with control subjects as well as with intervention subjects and change their method of instruction accordingly, which may not be practical over a long-term study period. Third, the participants at baseline and those at 4 years were not equivalent; however, it seems difficult to follow the same group of participants over the long term because the beneficial effects of a pharmaceutical intervention on clinical outcomes in COPD could have been masked by the nature of a progressive disease like COPD.

In conclusion, this study demonstrated the long-term effects of our network system focused on "providing patients with correct inhaler use" and "checking patients' inhalation technique at regular intervals" through community pharmacists. Our system resulted in improved adherence to inhalation therapy and a reduction in the frequency of exacerbations in COPD patients. Further research with a large number of participants is needed to confirm the validity of the NEPPIT system.

\section{Acknowledgments}

The authors would like to thank the staff of the outpatient clinic of Kitano Hospital for data collection.

\section{Disclosure}

The authors report no conflicts of interest in this work.

\section{References}

1. National Institutes of Health. NHLBI/WHO Workshop Report: National Institutes of Health, National Heart, Lung and Blood Institute, Update 2008. Global Strategy for the Diagnosis, Management, and Prevention of Chronic Obstructive Pulmonary Disease. Bethesda, MD: National Institute of Health; 2008.

2. Calverley PM, Anderson JA, Celli B, et al; for TORCH Investigators. Salmeterol and fluticasone propionate and survival in chronic obstructive pulmonary disease. N Engl J Med. 2007;356(8):775-789.

3. Tashkin DP, Celli B, Senn S, et al. A 4-year trial of tiotropium in chronic obstructive pulmonary disease. N Engl J Med. 2008;359(15): 1543-1554. 
4. Krigsman K, Nilsson JL, Ring L. Adherence to multiple drug therapies: refill adherence to concomitant use of diabetes and asthma/COPD medication. Pharmacoepidemiol Drug Saf. 2007;16(10):1120-1128.

5. Krigsman K, Moen J, Nilsson JL, Ring L. Refill adherence by the elderly for asthma/chronic obstructive pulmonary disease drugs dispensed over a 10-year period. J Clin Pharm Ther. 2007;32(6):603-611.

6. Haupt D, Krigsman K, Nilsson JL. Medication persistence among patients with asthma/COPD drugs. Pharm World Sci. 2008;30(5):509-514.

7. Molimard M, Raherison C, Lignot S, Depont F, Abouelfath A, Moore N. Assessment of handling of inhaler devices in real life: an observational study in 3811 patients in primary care. J Aerosol Med. 2003;16(3): 249-254.

8. Vestbo J, Anderson JA, Calverley PM, et al. Adherence to inhaled therapy, mortality and hospital admission in COPD. Thorax. 2009;64(11):939-943.

9. Takemura M, Mitsui K, Itotani R, et al. Relationships between repeated instruction on inhalation therapy, medication adherence, and health status in chronic obstructive pulmonary disease. Int J Chron Obstruct Pulmon Dis. 2011;6:97-104.

10. Takemura M, Mitsui K, Ido M, et al. Impact of a network system for providing proper inhalation technique by community pharmacists. J Asthma . 2012;49(5):535-541.

11. Erickson SR, Coombs JH, Kirking DM, Azimi AR. Compliance from self-reported versus pharmacy claims data with metered-dose inhalers. Ann Pharmacother. 2001;35(9):997-1003.

12. De Smet BD, Erickson SR, Kirking DM. Self-reported adherence in patients with asthma. Ann Pharmacother. 2006;40(3):414-420.

13. Takemura M, Kobayashi M, Kimura K, et al. Repeated instruction on inhalation technique improves adherence to the therapeutic regimen in asthma. J Asthma. 2010;47(2):202-208.

14. Morisky DE, Green LW, Levine DM. Concurrent and predictive validity of a self-reported measure of medication adherence. Med Care. 1986; 24(1):67-74.

15. Morisky DE, Ang A, Krousel-Wood M, Ward HJ. Predictive validity of a medication adherence measure in an outpatient setting. J Clin Hypertens (Greenwich). 2008;10(5):348-354.

16. Jones PW, Quirk FH, Baveystock CM, Littlejohns P. A self-complete measure of health status for chronic airflow limitation. The St George's Respiratory Questionnaire. Am Rev Respir Dis. 1992;145(6): 1321-1327.

17. Bouchet C, Guillemin F, Hoang Thi TH, Cornette A, Briançon S. Validation of the St George's questionnaire for measuring the quality of life in patients with chronic obstructive pulmonary disease. Rev Mal Respir. 1996;13(1):43-46.
18. Hajiro T, Nishimura K, Tsukino M, Ikeda A, Koyama H, Izumi T. Comparison of discriminative properties among disease-specific questionnaires for measuring health-related quality of life in patients with chronic obstructive pulmonary disease. Am J Respir Crit Care Med. 1998;157(3 Pt 1):785-790.

19. Basheti IA, Reddel HK, Armour CL, Bosnic-Anticevich SZ. Improved asthma outcomes with a simple inhaler technique intervention by community pharmacists. J Allergy Clin Immunol. 2007;119(6):1537-1538.

20. Armour C, Bosnic-Anticevich S, Brillant M, et al. Pharmacy Asthma Care Program (PACP) improves outcomes for patients in the community. Thorax. 2007;62(6):496-502.

21. Mehuys E, Van Bortel L, De Bolle L, et al. Effectiveness of pharmacist intervention for asthma control improvement. Eur Respir J. 2008;31(4): 790-799.

22. Self TH, Brooks JB, Lieberman P, Ryan MR. The value of demonstration and role of the pharmacist in teaching the correct use of pressurized bronchodilators. Can Med Assoc J. 1983;128(2):129-131.

23. McLean W, Gillis J, Waller R. The BC Community Pharmacy Asthma Study: A study of clinical, economic and holistic outcomes influenced by an asthma care protocol provided by specially trained community pharmacists in British Columbia. Can Respir J. 2003;10(4):195-202.

24. Cordina M, McElnay JC, Hughes CM. Assessment of a community pharmacy-based program for patients with asthma. Pharmacotherapy. 2001;21(10):1196-1203.

25. Barbanel D, Eldridge S, Griffiths C. Can a self-management programme delivered by a community pharmacist improve asthma control? A randomised trial. Thorax. 2003;58(10):851-854.

26. Khdour MR, Kidney JC, Smyth BM, McElnay JC. Clinical pharmacyled disease and medicine management programme for patients with COPD. Br J Clin Pharmacol. 2009;68(4):588-598.

27. Jarab AS, Alqudah SG, Khdour M, Shamssain M, Mukattash TL. Impact of pharmaceutical care on health outcomes in patients with COPD. Int J Clin Pharm. 2012;34(1):53-62.

28. Monninkhof E, van der Valk P, van der Palen J, van Herwaarden C, Partridge MR, Zielhuis G. Self-management education for patients with chronic obstructive pulmonary disease: a systematic review. Thorax. 2003;58(5):394-398.

29. Gallefoss F, Bakke PS, Rsgaard PK. Quality of life assessment after patient education in a randomized controlled study on asthma and chronic obstructive pulmonary disease. Am J Respir Crit Care Med. 1999;159(3):812-817.

30. McGeoch GR, Willsman KJ, Dowson CA, et al. Self-management plans in the primary care of patients with chronic obstructive pulmonary disease. Respirology. 2006;11(5):611-618.
International Journal of COPD

\section{Publish your work in this journal}

The International Journal of COPD is an international, peer-reviewed journal of therapeutics and pharmacology focusing on concise rapid reporting of clinical studies and reviews in COPD. Special focus is given to the pathophysiological processes underlying the disease, intervention programs, patient focused education, and self management protocols.

\section{Dovepress}

This journal is indexed on PubMed Central, MedLine and CAS. The manuscript management system is completely online and includes a very quick and fair peer-review system, which is all easy to use. Visit http://www.dovepress.com/testimonials.php to read real quotes from published authors. 